Raquel de Souza Ramos ${ }^{1}$ Antonio Marcos Tosoli Gomes ${ }^{1}$ Raphael Mendonça Guimarães ${ }^{2}$ Érick Igor dos Santos ${ }^{1}$

\title{
A JUDICIALIZAÇÃO DA SAÚDE CONTEXTUALIZADA NA DIMENSÃO PRÁTICA DAS REPRESENTAÇÕES SOCIAIS DOS PROFISSIONAIS DE SAÚDE
}

The judicialization of health contextualizes in the practical dimension of health care professionals social representations

${ }^{1}$ Universidade do Estado do Rio de Janeiro. Rio de Janeiro/RJ, Brasil.

${ }^{2}$ Universidade Federal do Rio de Janeiro. Rio de Janeiro/RJ, Brasil.

Correspondência: Raquel de Souza Ramos. E-mail: kakelramos@gmail.com.

Recebido em: 24/04/2016. Revisado: 31/10/2016. Aprovado: 21/02/2017. 


\section{RESUMO}

A judicialização da saúde é uma expressão cada vez mais presente no Brasil, materializada principalmente pelos mandados judiciais para a realização de procedimentos diagnósticos e terapêuticos, consultas, internações e dispensação de insumos médico-cirúrgicos. Este artigo visa a analisar e discutir os conteúdos da representação social da judicialização, contextualizada na dimensão prática das representações sociais dos profissionais de saúde. O estudo qualitativo, pautado na Teoria das Representações Sociais, entrevistou 40 profissionais em um hospital universitário e na central de regulação de procedimentos e leitos na cidade do Rio de Janeiro. A análise se deu pela técnica de análise de conteúdo temático-categorial, instrumentalizada pelo software NVivo, resultando em 725 unidades de registro, distribuídas em 34 temas. Identificou-se que os profissionais apresentam um posicionamento negativo diante da realidade imposta pela judicialização, embora reconheçam esse recurso como necessário mediante a crise da saúde pública. Considerando a representação social como determinante de práticas, conclui-se que as representações oriundas deste estudo se encontram em fase de consolidação e podem influenciar a mudança das práticas dos profissionais em busca de melhorias na assistência direta aos usuários, caracterizando-se, portanto, um desafio maior no sentido de fazer avançar a democracia e a cidadania.

\section{Palavras-Chave}

Decisões Judiciais; Direito à Saúde; Percepção Social; Política de Saúde; Sistema Único de Saúde.

\section{ABSTRACT}

The judicialization of health is an expression increasingly present in Brazil, materialized mainly by court orders for the performance of diagnostic and therapeutic procedures, consultations, hospitalizations and dispensation of medical and surgical supplies. The study aims to analyze and discuss the contents of the social representations of judicialization contextualized in the practical dimension of the social representations of health care professionals. This is a qualitative study, based on the Theory of Social Representations, conducted with 40 professionals at a university hospital and the center of regulation of procedures and beds in the city of Rio de Janeiro, with 40 semi-structured interviews, that were analyzed through thematic-categorial content analysis, instrumentalized by NVivo software, resulting in 725 units of analysis, distributed in 34 themes. We identified that health care professionals have a negative position towards the reality imposed by the judicialization, however they recognize this recourse as necessary in face of the Brazilian public health crisis. Considering the social representation as a determinant of practices, it was concluded that social representations arising from this study are in the final stages of consolidation and may contribute to change the practices of health professionals in search for improvements in the users' direct care, embodying a greater challenge in the sense of promoting democracy and citizenship.

\section{Keywords}

Brazilian National Health System; Health Policy; Juridical Decisions; Right to Heatlh; Social Perception 


\section{Introdução}

A judicialização da saúde é uma expressão cada vez mais presente no campo da saúde no Brasil, materializada principalmente pelos mandados judiciais para a realização de procedimentos diagnósticos e terapêuticos, consultas, internações e dispensação de insumos médico-cirúrgicos. Por judicialização da saúde, entende-se a reivindicação da saúde como um direito ${ }^{1}$, que ocorre quando o Poder Judiciário passa a ter a função de tomar decisões coletivamente vinculantes, sobrepondo-as ao arcabouço normativo do Sistema Único de Saúde (SUS)2.

No ordenamento jurídico brasileiro, o artigo 196 da Constituição Federal ${ }^{3}$ estabelece que a saúde é um direito e é considerada como bem público inalienável. A Lei Orgânica da Saúde (Lei n. 8.080/19904) concebeu o SUS como um conjunto de ações e serviços de saúde proporcionados pelo Estado; desenvolvidos respeitando os princípios éticos de universalidade, integralidade e equidade; e organizados de forma descentralizada, hierarquizada, regionalizada e com participação social ${ }^{5}$. O SUS vem enfrentando obstáculos desde a sua implantação, e o direito à saúde nem sempre vem sendo cumprido. É notório que cada vez mais cidadãos recorrem ao Judiciário para reivindicar seu direito sanitário e garantir o acesso a demandas não acolhidas. Assim, o fato de se recorrer às instâncias jurídicas para acessar o que está constitucionalmente garantido configura-se em um grande paradoxo quando se analisa que a política de saúde se desenvolve em um Estado de Direito, com amplo espaço democrático, envolvendo a sociedade civil e os poderes Legislativo, Executivo e Judiciário nas decisões e discussões sobre os rumos da política de saúde.

Do ponto de vista das práticas profissionais, por vezes, a escassez de recursos diferenciados e de tecnologias de cuidado, fruto da operacionalização da racionalidade médica e da mercantilização da saúde, pode gerar relações conflituosas entre profissionais, usuários e serviços de saúde.

Observa-se, portanto, um risco de disfunção do sistema ao se desenvolver a via judicial como principal meio para garantir acesso, com o Poder Judiciário configurando-se como mais uma porta de entrada no sistema, descaracterizando as bases teóricas e conceituais amplamente discutidas sobre o acesso ao SUS.

\footnotetext{
${ }^{1}$ MARQUES, S. B. Judicialização do direito à saúde. Revista de Direito Sanitário, São Paulo, São Paulo, v. 9, n. 2, p. 65-72, jul./out. 2008. Disponível em: <https://www.revistas.usp.br/rdisan/article/view/13117/14920>. ${ }^{2}$ CAMPILONGO, C. F. O direito na sociedade complexa. São Paulo: Max Limonad, 2000.

${ }^{3}$ Brasil. Constituição da República Federativa do Brasil de 1988. Disponível em: <http://www.planalto.gov.br/ ccivil_03/Constituicao/ConstituicaoCompilado.htm>. Acesso em: 13 mai 2016.

${ }^{4}$ BRASIL. Lei n. 8.080, de 19 de setembro de 1990. Dispõe sobre as condições para a promoção, proteção e recuperação da saúde, a organização e o funcionamento dos serviços correspondentes e dá outras providências. Disponível em: <http://www.planalto.gov.br/ccivil_03/leis/L8080.htm>. Acesso em: 13 out. 2017.

${ }^{5}$ BRASIL. Lei n. 8.142, de 28 de dezembro de 1990. Dispõe sobre a participação da comunidade na gestão do Sistema Único de Saúde - SUS e sobre as transferências intergovernamentais de recursos financeiros na área da saúde e dá outras providências. Disponível em: <http://www.planalto.gov.br/ccivil_03/leis/L8142. htm>. Acesso em: 13 out. 2017.
} 
Em estudos direcionados pela Teoria das Representações Sociais, elaborada por Serge Moscovici, em 1961' , a escolha do fenômeno a ser investigado não estabelece automaticamente o objeto de pesquisa. $\mathrm{O}$ aporte para a definição do objeto de estudo está em Sá quando o autor afirma que

A construção do objeto de pesquisa pode ser vista como um processo decisório, pelo qual transformamos conceitualmente um fenômeno do universo consensual em um problema do universo reificado e, em seguida, selecionamos os recursos teóricos e metodológicos a serem usados para a solução do problema ${ }^{7}$.

O mesmo autor sustenta, ainda, que é fundamental o estabelecimento de uma correspondência entre o pensamento social (as representações sociais) e as práticas sociais da população estudada e alerta que

a "espessura" ou a "relevância" de um objeto - que justificaria a existência de representações - pode ser traduzida da seguinte maneira: o objeto em questão "se encontra implicado, de forma consistente, em alguma prática do grupo, aí incluída a da conversação e a da exposição aos meios de comunicação de massa"s.

Também deve estar claro para o pesquisador que, na definição do objeto de estudo, "a representação que os liga [atores sociais e objeto de representação] é um saber efetivamente praticado, que não deve ser apenas suposto, mas sim detectado em comportamentos e comunicações que de fato ocorram sistematicamente".

Mediante o exposto, percebeu-se que a judicialização da saúde atende aos requisitos sugeridos pelo autor, surgindo, portanto, a possibilidade de considerá-la como um objeto de representação.

Assim, a partir dessas reflexões, delimitou-se como objeto de estudo a judicialização das ações e dos serviços de saúde no âmbito do SUS e suas representações sociais pelos profissionais, reguladores e gestores de saúde. Dessa forma, o presente estudo tem como objetivo analisar o processo de judicialização da saúde no Brasil, no âmbito do SUS, a partir dos profissionais de saúde envolvidos nesse processo. Apoiando a justificativa para a realização deste estudo, Marques $^{10}$ assevera que é fundamental que juízes, promotores de justiça, gestores públicos, sociedade civil, operadores de direito, sanitaristas, membros da academia, dentre outros envolvidos na temática, discutam o assunto de forma ampla e proponham soluções conjuntas para minimizar o conflito sociopolítico evidenciado.

\footnotetext{
${ }^{6} \mathrm{MOSCOVICI}$, S. La psychanalyse son image et son public. Paris: Presses Universitaires de France, 1976. ${ }^{7}$ SÁ, C. P. A construção do objeto de pesquisa em representações sociais. Rio de Janeiro: EdUERJ, 1998. p. 26. ${ }^{8}$ Id. Ibid., p. 50.

9 Id., loc. cit.

${ }^{10}$ MARQUES, S. B. op. cit., p.65-72.
} 
Para o desenvolvimento do presente estudo, optou-se pelo referencial da Teoria das Representações Sociais, que considera que as representações coletivas traduzem a maneira como o grupo pensa sobre suas relações com os objetos que o afetam. Para compreender como a sociedade representa a si mesma e ao mundo que a rodeia, é preciso pensar sobre a natureza da sociedade, e não sobre a natureza dos indivíduos ${ }^{11}$. A Teoria das Representações Sociais permite uma compreensão das construções simbólicas, das práticas e das atitudes ${ }^{12}$. Assim, a identificação das representações sociais dos profissionais que atuam no SUS, acerca da judicialização da saúde, permitirá uma ampliação do debate e uma melhor compreensão das complexas teias estabelecidas nesse contexto.

\section{Metodologia}

O estudo é qualitativo, pautado na abordagem processual da Teoria das Representações Sociais proposta por Denise Jodelet ${ }^{13}$, que coloca em evidência a forma pela qual as representações sociais encontram-se vinculadas ao cotidiano dos sujeitos. Nessa vertente, os discursos, os comportamentos e as práticas sociais de indivíduos e grupos sociais, nos quais as representações se manifestam, proporcionam a veiculação das mesmas.

A pesquisa foi desenvolvida em dois campos na cidade do Rio de Janeiro: um hospital público universitário da esfera estadual que presta atendimentos em casos de alta e média complexidade e que executa as ordens judiciais; e uma Central de Regulação de Serviços de Saúde também da esfera estadual que recebe tais ordens e recorre aos recursos da rede para atendê-las.

Foram abordados, por meio de um questionário sociodemográfico e entrevista semiestruturada, 40 profissionais do corpo permanente das instituições, em atuação há mais de um ano e que tenham vivenciado situações relativas à judicialização da saúde. Tais critérios foram estabelecidos para garantir que os participantes tenham um maior contato com o objeto de estudo, o que influencia diretamente a definição da representação social.

Os dados sociodemográficos foram organizados em um banco de dados no software Microsoft Office Excel 2010, sendo analisadas as seguintes variáveis: sexo, faixa etária, estado conjugal, nível de escolaridade, tempo de trabalho, categoria profissional e localização da atuação no cenário.

A análise dos depoimentos se deu pela técnica de análise de conteúdo temática, sistematizada por Oliveira ${ }^{14}$, e operacionalizada pelo software QSR Nvivo.

\footnotetext{
${ }^{11} \mathrm{MOSCOVICl}, \mathrm{S}$. op. cit.

${ }^{12}$ Id. Ibid.

${ }^{13}$ JODELET, D. Folies et représentations sociales. Paris: PUF, 1989.

${ }^{14}$ OLIVEIRA, D. C. Análise de conteúdo temático-categorial: uma proposta de sistematização. Rev. Enferm. UERJ, Rio de Janeiro, v.16, n.4, p. 569-576, out./dez. 2008. Disponível em: <http://www.facenf.uerj.br/ v16n4/v16n4a19.pdf>.
} 
O projeto foi submetido ao Comitê de Ética e Pesquisa do Hospital Universitário Pedro Ernesto, aprovado no Parecer Consubstanciado CAAE 14933613.1.0000.5259 de 26/04/2013.

\section{Resultados}

Da totalidade dos sujeitos, $84 \%$ atuavam no hospital e $16 \%$ na Central de Regulação. Este último grupo está em menor quantidade devido a uma mudança na forma de contratação, estando tal quantitativo de reguladores em conformidade com critérios de inclusão.

A categoria profissional de enfermeiros correspondeu a $49 \%$, seguida por médicos (34\%). Os técnicos de enfermagem contabilizaram 13\% do total de investigados, e $4 \%$ eram assistentes sociais. Assim, 13\% possuíam nível de escolaridade médio e $87 \%$, nível superior. A escolha dessas categorias justifica-se pelo fato de que, no universo dos profissionais de saúde, elas são as que têm um contato mais próximo com o objeto de estudo, o que é fundamental para a identificação da representação social.

Em relação à distribuição por sexo, 34\% eram do sexo masculino e $66 \%$, do sexo feminino. Esse dado se relaciona com a variável da categoria profissional, já que a enfermagem e o serviço social são profissões eminentemente femininas.

A maioria dos sujeitos investigados, $54 \%$, era casada; $38 \%$ eram solteiros; $7 \%$, separados ou desquitados; e apenas $1 \%$ era viúvo.

A faixa etária entre 36 e 40 anos de idade correspondeu a 20\%. Destacam-se ainda sujeitos com idade entre 46 e 50 anos e de 31 a 35 anos. Apenas $9 \%$ eram profissionais com mais de 56 anos, o que pode ser decorrente da concessão do benefício de aposentadoria a partir dos 55 anos de idade.

Considerando que a judicialização é um fato relativamente recente - o registro histórico de seu início remonta à década de $1990^{15}, 41 \%$ dos sujeitos (os com idade superior a 46 anos) provavelmente assistiram à introdução de demandas de atendimento via judicialização ao longo da trajetória profissional.

Sobre a variável "tempo de trabalho", $34 \%$ estavam em início de carreira, desempenhando atividades profissionais entre um e cinco anos; $37 \%$ tinham atuação profissional havia mais de 16 anos, configurando um grupo com experiência profissional consolidada. Essa relação entre sujeitos e tempo de atuação no campo possibilita o estabelecimento de um posicionamento crítico diante da realidade

\footnotetext{
${ }^{15}$ VENTURA, M. et al. Judicialização da saúde, acesso à justiça e a efetividade do direito à saúde. Physis, Rio de Janeiro, v. 20, n. 1, p. 77-100, 2010. Disponível em: <http://www.scielo.br/scielo.php?script=sci_arttex t\&pid=S0103-73312010000100006 >. http://dx.doi.org/10.1590/S0103-73312010000100006.
} 
institucional, contribuindo para a elaboração e consequente captação das representações sociais do objeto deste estudo.

A análise de conteúdo dos depoimentos resultou em 725 unidades de registro (UR) e 34 temas, organizados em duas subcategorias, e destacou a forma como os profissionais e as instituições de saúde, o sistema judiciário e o próprio sistema de saúde interagem com o objeto dentro do espaço social. Realizando uma aproximação com a Teoria das Representações Sociais, os dados expressam a dimensão prática da representação social, que se relaciona aos discursos e experiências dos profissionais em seus aspectos objetivos, subjetivos e simbólicos, em uma perspectiva dinâmica de constituição e intercâmbio entre o objeto, a representação e os sujeitos estabelecidos no contexto social em que se inserem, onde as práticas funcionam como agentes de transformação da representação ${ }^{16}$.

A primeira subcategoria encontra-se organizada em 21 temas e 438 UR e aborda como os profissionais lidam com a judicialização no cotidiano de trabalho, possibilitando compreender de que modo ela interfere nas práticas sociais, nas atitudes e nas condutas em relação ao objeto de representação. Essa subcategoria representa a forma como o processo de assimilação dos fatos se dá no campo social, como os mesmos são compreendidos pelos sujeitos, e evidencia, igualmente, a forma como o conhecimento construído se expressa por intermédio da comunicação e do comportamento.

Ficou evidente que a intervenção judicial no campo da saúde suscita tensões no cotidiano desses profissionais. A influência de instâncias e sujeitos que não pertencem aos serviços de saúde impacta a rotina de trabalho, alterando os protocolos institucionais que se propõem a ofertar um tratamento universal e equânime a usuários que apresentam necessidades similares, e não baseados em imposições de profissionais que não apresentam competência técnica e não vivenciam a realidade das instituições de saúde.

Um dos principais aspectos tratados nessa dimensão refere-se ao planejamento. O macroplanejamento da política de saúde se dá dentro das diretrizes estabelecidas pelo sistema de planejamento do SUS. A ferramenta gerencial Plano de Saúde expressa as políticas e os compromissos de saúde nas esferas de gestão e é o alicerce da execução, do monitoramento, da avaliação e da gestão do sistema.

Já a Programação Anual de Saúde promove a operacionalização das intenções do Plano de Saúde, principalmente metas e recursos financeiros a serem empregados para alcançar os objetivos que, por sua vez, são estabelecidos de acordo com estudos demográfico, socioeconômico e epidemiológico da população que

${ }^{16}$ ROUQUETE, M. L. Representações e práticas sociais: alguns elementos teóricos. In: MOREIRA, A. S. P.; OLIVEIRA, D. C. (Orgs.). Estudos interdisciplinares em representação social. 2. ed. Goiânia: AB Ed., 2000. p. 27-38. 
identificam os principais problemas de saúde de grupos populacionais, permitindo que os gestores ajam com certa previsibilidade dos recursos ${ }^{17}$.

Ressalta-se que a administração pública utiliza a licitação pública para garantir vantagens aos cofres públicos na compra e contratação de serviços ${ }^{18}$.

Os recursos judicializados, destinados a procedimentos não padronizados, nem sempre estão previstos no planejamento anual, gerando custos altos e inesperados. Dado o prazo exímio para seu cumprimento, é necessário dispensar a licitação para a aquisição imediata do recurso a ser concedido em função de decisões judiciais, impactando o orçamento.

Os profissionais corroboraram essas assertivas conforme explicitado nos seguintes trechos:

Entrevista 15 - Médico: "E, aí, quando você chega no final do ano e vê que o orçamento não deu, você vê que gastou, em média, mais $30 \%$ do que você planejou para a assistência em saúde, em qualquer esfera de governo, em mandado judicial de medicamentos."

Entrevista 3 - Assistente Social: "Então você sai de uma área de segurança, não de conforto, para um terreno desconhecido porque você não consegue dimensionar os recursos para o atendimento do que a Justiça manda, você não conhece a história da pessoa e não consegue prever o que pode acontecer."

O gasto via determinação judicial desestabiliza as contas dos serviços de saúde e inviabiliza o planejamento e o desenvolvimento das ações coletivas ${ }^{19}$. Além do efeito negativo na governabilidade e gestão das políticas de saúde ${ }^{20}$, a judicialização colabora para o aprofundamento das iniquidades, ao promover o acesso de apenas um segmento ou indivíduo a determinado recurso ${ }^{21}$, situação salientada pelos profissionais entrevistados:

\footnotetext{
${ }^{17}$ BRASIL. Ministério da Saúde. Secretaria-Executiva. Subsecretaria de Planejamento e Orçamento. Sistema de planejamento do SUS: uma construção coletiva: instrumentos básicos. 2. ed. Brasília-DF, 2009. 56p. Disponível em: <http://bvsms.saude.gov.br/bvs/publicacoes/caderno2_planejasus_2ed.pdf>.

${ }^{18}$ Brasil. Lei n. 8.666, de 21 de junho de 1993. Regulamenta o art. 37, inciso XXI, da Constituição Federal, institui normas para licitações e contratos da Administração Pública e dá outras providências. Disponível em: <http://www.planalto.gov.br/ccivil_03/leis/L8666cons.htm>. Acesso em: 13 out. 2017.

${ }^{19}$ MACHADO, F. R. S.; Dain, S. A audiência pública da saúde: questões para a judicialização e para a gestão de saúde no Brasil. Rev. Adm. Pública, Rio de Janeiro, v. 46, n. 4, p. 1017-1036, jul./ago. 2012. Disponível em <http://www.scielo.br/scielo.php?script=sci_arttext\&pid=S0034-76122012000400006\&lng=pt\&nrm =iso>. Acesso em: 23 maio 2014. http://dx.doi.org/10.1590/S0034-76122012000400006.

${ }^{20}$ MOCELIN, C. E. Demandas judiciais na saúde pública: instrumentos para a efetivação do direito à saúde e/ ou novos arranjos na gestão e organização do SUS. Rev. gestão desenvolv. Contexto - GEDECON, Cruz Alta, v. 1, n. 1, p. 100-117, 2013. Disponível em: <http://revistaeletronica.unicruz.edu.br/index.php/GEDECON/ article/view/311/226>.

${ }^{21}$ PINHEIRO, R; Mattos, R. A. (Org.). Os sentidos da integralidade na atenção e no cuidado à saúde. Rio de Janeiro: CEPESC/UERJ- IMS/ABRASCO, 2001
} 
Entrevista 5 - Médico: "Planeja-se um serviço ou ação e, durante sua execução, este planejamento é atropelado pelas ações judiciais, interrompendo o fluxo normal de atendimento, fazendo com que alguns demorem mais para ser atendidos ou até mesmo que fiquem sem assistência."

Entrevista 9 - Enfermeiro: "Quer dizer, ele quebra totalmente o serviço que você tem, aquilo que você tem e até a confiança do doente porque, se você diz que sua cirurgia está programada, vem alguém judicialmente e pega a sua vez, isso se torna um transtorno."

A ampliação da atuação do Judiciário no campo da saúde impacta não só a gestão, mas também influencia o processo de tomada de decisão dos profissionais ${ }^{22}$. Esses depoimentos revelam a interferência das decisões judiciais no planejamento global e local - o que, por contingência, interfere no processo de trabalho dos profissionais.

Entrevista 17 - Médico: "Isso é difícil, às vezes toma nosso dia todo tentando resolver e todo o resto de rotina fica parada, e eu me sinto mais um regulador do Judiciário do que regulador do SUS."

Entrevista 12-Enfermeiro: "É tentar reorganizar o que foi planejado, o que está sendo feito para incluir aquele cliente e solicitar a assistência dele, a compra de material ou medicamentos. E isso causa um transtorno muito grande, que pode muitas vezes até demandar tempo da assistência de outro cliente que está precisando de urgência."

No campo da organização do processo de trabalho, a natureza do trabalho em saúde prima pelo encontro de pessoas que apresentam suas necessidades de saúde com outras dotadas de conhecimentos técnicos e científicos capazes de solucionar um problema, mediante o estabelecimento de critérios de prioridades de atenção que possam garantir o atendimento pleno de todos os que dependem dos cuidados da equipe de saúde ${ }^{23}$.

Assim, a judicialização vem prejudicando a organização do trabalho em saúde, considerando a exigibilidade de atendimento prioritário e imediato dos sujeitos que ingressam no sistema de saúde pela Justiça. Além da desorganização dos processos de trabalho, os profissionais de saúde enfrentam entraves burocráticos e operacionais no cumprimento dos mandados - no caso de internações, o processo de busca de vagas é o entrave inicial.

Entrevista 22 - Enfermeiro: "A gente vê que a Direção fica enlouquecida com isso porque tem que ter a vaga de qualquer forma."

${ }^{22}$ VENTURA, M. et al. op. cit.

${ }^{23}$ GARLET, E. R. et al. Organização do trabalho de uma equipe de saúde no atendimento ao usuário em situações de urgência e emergência. Texto contexto enferm., Florianópolis, v. 18, n. 2, p.2 66-272, abr./jun. 2009. Disponível em: <http://www.scielo.br/pdf/tce/v18n2/09>. 
Entrevista 17 - Médico: “A gente dá um recibo e começa a saga de procurar vaga. Primeiro a gente acessa o sistema para ver se, por milagre, tem alguma vaga e, se não tiver, vamos para o telefone, ligando de unidade em unidade para tentar resolver."

A falta de leitos de internação na rede SUS é, de fato, uma das dificuldades enfrentadas pela população que necessita desse recurso para a recuperação de sua saúde. Os usuários vêm enfrentando obstáculos para acessar leitos, principalmente os de média complexidade e de alto custo, sendo as solicitações de vagas uma das principais demandas levadas ao Judiciário ${ }^{24,25}$.

Outro fato notório é que, quando a Justiça facilita o acesso ao recurso, a família tende a ser mais incisiva no trato com a equipe, principalmente no que tange ao atendimento imediato de demandas que vão surgindo durante a internação.

Entrevista 6 - Enfermeiro: "Se ele necessita de um determinado cuidado e se eu avaliar que tem um outro paciente que necessita de um cuidado mais urgente, eu vou atender primeiro o paciente que precisa do cuidado urgente, e não a ele só porque ele entrou por um mandado judicial. Porque, a partir do momento que ele está aqui deitado, ele é igual a qualquer outro."

Esses profissionais procuram atender aos usuários admitidos pela Justiça da mesma maneira como atendem aos demais, visando a garantir o princípio de isonomia e de igualdade de direitos, contribuindo para a prática da igualdade constitucional e do princípio da equidade. Entretanto, manifestam um sentimento de desconforto ao serem obrigados a atender aos mandados.

Entrevista 25 - Assistente Social: “Assim, já vi médico muito contrariado porque tem que atender uma pessoa que entrou com mandado judicial."

Entrevista 20 - Médico: "Causa uma indignação e que gera um conflito na equipe, um inconformismo ainda mais quando esses mandados se acumulam, se repetem a cada semana, isso te cansa."

Esse posicionamento acontece em razão da discordância técnica dos profissionais com as decisões judiciais e da dificuldade de estabelecimento de um diálogo com o Judiciário para eventual argumentação.

\footnotetext{
${ }^{24}$ SPEDO, S. M.; Pinto, N. R. S.; Tanaka, O. Y. O difícil acesso a serviços de média complexidade do SUS: o caso da cidade de São Paulo, Brasil. Physis, Rio de Janeiro, v. 20, n. 3, 2010. Disponível em: <http://www.scielo. br/scielo.php?script=sci_arttext\&pid=S0103-73312010000300014\&lng=en\&nrm=iso>. Acesso em: 03 mar. 2014. http://dx.doi.org/10.1590/S0103-73312010000300014.

${ }^{25}$ GOMES, F. F. C. A judicialização da saúde em Minas Gerais: uma avaliação dos processos judiciais relacionados aos procedimentos ambulatoriais e hospitalares no período 1999-2009. 2013. 98f. Dissertação (Mestrado em Saúde Pública) - Faculdade de Medicina, Universidade Federal de Minas Gerais, Belo Horizonte, 2013.
} 
Entrevista 26 - Assistente Social: "Não percebo uma possibilidade maior de diálogo com os juízes. Isso tem sido bastante complicado. Essa conversa e esse diálogo têm sido mediados apenas por documento. Às vezes, esse documento chega lá e inicialmente já é determinado."

Entrevista 20 - Médico: "Eu lamento muito, porque o Judiciário está muito inerte em relação à prática de dialogar.”

Urge o estabelecimento de diálogo entre as diversas instituições e entre os poderes para agilizar o atendimento, de forma a não ferir a política de saúde e a não prejudicar o atendimento da coletividade em favor do atendimento de um indivíduo. A "emergência desse diálogo toma contornos cada vez mais visíveis, sob pena de inviabilizar a gestão do Sistema Único de Saúde"26. Portanto, é fundamental a harmonia entre os poderes para efetivar o direito à saúde, sendo essa relação harmoniosa facilitada pela prática do diálogo, um mecanismo que faz parte da dinâmica natural de um Estado de Direito, como é o caso do brasileiro ${ }^{27}$.

A segunda subcategoria é composta por 287 UR e 13 temas, que mostram a interferência da judicialização no funcionamento do SUS e a interferência do Estado no estabelecimento da judicialização como realidade nos serviços de saúde.

Os discursos revelam uma forte ligação das falhas do sistema com a judicialização. O SUS surgiu no cenário sanitário brasileiro no início da década de 1990 com o propósito de alterar a situação da desigualdade na assistência à saúde da população observada antes de sua implantação, sendo construído na intenção de concretizar o conceito de saúde como direito.

A judicialização, conforme os depoimentos, está colocando em risco esse sistema, já que as ações normalmente não beneficiam o coletivo e não respeitam as diretrizes dessa política, tendendo a promover uma descaracterização de sua proposta.

Um dos destaques dos entrevistados versa sobre os princípios do SUS, que passam a ser praticados de maneira distorcida no atendimento das medidas judiciais.

Entrevista 30 - Técnico de Enfermagem: "É meio que um sistema paralelo de saúde, hoje tem o SUS e o SJS, o sistema judicial de saúde."

Entrevista 7 - Enfermeiro: "Eu acho que, quando tem uma decisão de mandado, isso é completamente contrário ao SUS, até descaracteriza completamente."

\footnotetext{
${ }^{26}$ FERREIRA, S. L.; COSTA, A. M. Núcleos de assessoria técnica e judicialização da saúde: constitucionais ou inconstitucionais? Rev. Seção Judic. Rio de Janeiro, Rio de Janeiro, v. 20, n. 36, p. 219-240, abr. 2013. Disponível em: <https://bdjur.stj.jus.br/jspui/bitstream/2011/74787/nucleos_assessoria_tecnica_ferreira.pdf>.

${ }^{27}$ LEÃO, T. M. Direito sanitário: saúde e direito, um diálogo possível. Revista de Direito Sanitário, São Paulo, v. 12, n. 1, p. 277-292, jun. 2011. Disponível em: <http://www.revistas.usp.br/rdisan/article/ view/13244/15060>. Acesso em: 26 ago. 2012.
} 
Os princípios, competências e responsabilidades não têm sido considerados e determinadas decisões judiciais podem desestruturar o SUS ${ }^{28}$. Essa possibilidade de desestruturação foi assinalada pelos depoentes, quando afirmam que as decisões judiciais são contrárias ao SUS, inclusive nomeando o novo sistema que surge: o "sistema judicial de saúde".

Cabe destacar, ainda, que o modelo de organização preconizado se fundamenta no princípio da integralidade, sendo este o cerne da atenção em saúde ${ }^{29}$. A integralidade pode ser assumida como sendo uma ação social resultante da permanente interação dos atores na relação entre demanda e oferta, em planos distintos de atenção à saúde (plano individual - onde se constrói a integralidade no ato da atenção individual; e plano sistêmico - onde se garante a integralidade das ações na rede de serviços), nos quais os aspectos subjetivos e objetivos são considerados ${ }^{30}$.

A fala de um dos sujeitos destaca a maneira como a judicialização interfere no cumprimento desse princípio:

Entrevista 2 - Enfermeiro: "Mas, no fundo no fundo, muitas vezes os problemas não são da área da saúde. Eles extrapolam a área da saúde. Muitas vezes são da área social, da área de segurança ou de outras áreas que não atenderam aquela demanda daquele usuário e aí acabaram resvalando na saúde. Só que o Judiciário não ataca esses problemas também."

Essas afirmações corroboram estudos na área que concluíram que os magistrados têm interpretado a integralidade de maneira diferente do aparato teórico e jurídico do SUS, já que grande parte das sentenças se preocupa com o atendimento de determinada doença por meio de recursos diagnósticos e terapêuticos nem sempre incorporados ao SUS, mesmo que estejam disponíveis alternativas terapêuticas com eficácia comprovada. Portanto, as decisões não levam em conta os demais fatores determinantes do adoecimento, indo na contramão do conceito ampliado de saúde para além da inexistência de doença.

Entrevista 5 - Médico: "Integralidade para quê? É só para fazer o cateterismo e ponto. E todo o resto? Não precisa? A alimentação está adequada? A hipertensão está sendo adequadamente tratada, tem condições de acessar o sistema, tem renda que garanta o mínimo para se ter dignidade?"

\footnotetext{
${ }^{28}$ SANTOS, L. A gestão do SUS: limites de sua autonomia diante da judicialização da saúde, das ações administrativas e judiciais do Ministério Público e da atuação dos órgãos de controle. In: BRASIL. Ministério do Planejamento Gestão e Orçamento. Seminário Direito, Gestão e Democracia Limites da Autonomia e do Controle do Poder Executivo. Brasília-DF: Imprensa Nacional, 2010. p. 88-95.

${ }^{29}$ Id. Ibid.

${ }^{30} \mathrm{MEDICl}$, A. C. Judicialização, integralidade e financiamento da saúde. Diagn. Tratamento. São Paulo, v. 15, n. 2, p. 81-86, 2010. Disponível em: <http://files.bvs.br/upload/S/1413-9979/2010/v15n2/a81-87.pdf>. Acesso em: 05 out. 2011.
} 
O princípio da universalidade é compreendido como a garantia de todo cidadão ao direito de acesso aos serviços públicos de saúde ou, quando estes se encontram inexistentes, à rede complementar. Considera-se, ainda, que a universalidade refere-se ao "acesso à saúde como direito público subjetivo e integrante dos direitos da cidadania" ${ }^{2}$. Em uma aproximação com a judicialização da saúde, encontra-se um contrassenso: as decisões judiciais garantem o acesso, mas também fazem com que não haja o cumprimento das premissas do SUS, dado o caráter de atendimento predominantemente individual que essas ações fomentam, conforme destacaram os depoimentos:

Entrevista 21 - Assistente Social: "A população em sua totalidade não consegue ter acesso, só quem judicializa. Vide o exemplo que te dei, com isso se quebra também a universalidade."

Entrevista 23 - Enfermeiro: "Se o SUS tem que atender a todos, o mandado faz exatamente o oposto, o que é um contrassenso, ou seja, os mandados não cumprem o papel de levar a saúde a todo mundo."

Estudiosos da temática ${ }^{32}$ sublinham o fato de que as decisões judiciais tutelam somente quem acessa o Judiciário e reconhecem que este acesso se dá apenas a uma minoria. Outro apontamento é que, considerando-se o direito à saúde como um direito social e que essa modalidade de direito objetiva a redução de desigualdades, a prestação sanitária assegurada pela judicialização, principalmente de ações individuais, não se encontra em sintonia com o princípio da igualdade substancial, garantido na Constituição Federal de 1988.

A equidade é outro princípio que se encontra dissonante dos preceitos teóricos do SUS na judicialização da saúde.

Entrevista 26 - Assistente Social: "Quando a gente pensa em equidade, por exemplo, a gente está falando na possibilidade de pensar o direito não dentro de uma padronização, mas dentro daquilo que cada um necessita para ter acesso à saúde."

Entrevista 22 - Enfermeiro: "O SUS diz que todos têm que ser tratados com equidade, mas aí o outro que está na fila passa a ser tratado de forma desigual."

Por equidade, entende-se: oferecer ações e serviços para reduzir disparidades sociais e regionais, buscando maior equilíbrio social ${ }^{33}$. As decisões judiciais

\footnotetext{
${ }^{31}$ BRASIL. Lei Federal n. 8.080, de 19 de setembro de 1990, cit.

${ }^{32}$ SARLET, F.; Figueiredo, M. F. Algumas considerações sobre o direito fundamental à proteção e promoção da saúde aos 20 anos da Constituição Federal de 1988. Versão originalmente publicada na Revista de Direito do Consumidor, [S. I.], v. 17, n. 67, p. 125-172, 2008. Disponível em: <http://www.stf.jus.br/arquivo/ cms/processoAudienciaPublicaSaude/anexo/O_direito_a_saude_nos_20_anos_da_CF_coletanea_ TAnia_10_04_09.pdf>. Acesso em:16 set. 2011.

${ }^{33}$ BRASIL. Ministério da Saúde. Secretaria Executiva. Sistema Único de Saúde (SUS) descentralização. Brasília-DF, 2000. 32p.
} 
tendem a aprofundar mais ainda as desigualdades em saúde, uma vez que apenas o grupo que consegue recorrer ao Judiciário tem acesso a um determinado recurso. A judicialização não garante que determinado recurso esteja disponível a todos e, uma vez que os custos de um atendimento individual tendem a ser mais altos, é necessário realocar verbas, contribuindo para a perpetuação das iniquidades em saúde.

Os sujeitos da pesquisa destacaram também os princípios de regionalização e hierarquização.

Entrevista 19 - Médico: "Muitas, mas muitas vezes mesmo, eu já regulei paciente da Baixada para hospital na cidade do Rio de Janeiro, então a regionalização também acaba."

Entrevista 15 - Médico: "Hierarquizar é você escalonar os acessos e também, em cada nível de acesso, você definir prioridades em relação aos pacientes. Mas como fazer isso se o que me resta é acatar a ordem?”

Em relação à regionalização e à hierarquização, ressalta-se que esses princípios significam, respectivamente, a distribuição espacial dos serviços de modo a atender às necessidades da população por regiões e em diferentes níveis de complexidade ${ }^{34}$. A regionalização da saúde pode ser entendida como um processo de organização das ações e dos serviços de saúde em uma determinada região, visando à universalidade do acesso, à integralidade do atendimento e à equidade e otimização dos recursos disponíveis na rede. Esse princípio tem forte interface com o princípio da descentralização político-administrativa, que privilegia as ações de saúde na lógica da municipalização. Entretanto, quando a judicialização desconsidera esse arranjo instituído, colabora para o enfraquecimento do sistema e da aplicabilidade de suas propostas no campo prático.

Outro apontamento que deriva das representações dos sujeitos trata dos efeitos deletérios no SUS. A judicialização vem fomentando a criação de um sistema paralelo de saúde, no qual a Justiça vem se estruturando como uma porta de entrada alternativa.

Entrevista 3 - Assistente Social: "Ela veio como um atalho que a população identificou como possível para enfrentar a falta de acesso."

Entrevista 5 - Médico: "Desrespeita toda a lógica do sistema. A porta de entrada agora é o Judiciário."

O SUS foi pensado para garantir acesso às ações e aos serviços de saúde aos cidadãos, sendo estes ofertados pelo Estado e estando vedada a criação de sistemas paralelos de saúde por qualquer entidade pública ${ }^{35}$.

\footnotetext{
${ }^{34}$ BRASIL. Ministério da Saúde. Regionalização Solidária e Cooperativa. Orientações para sua implementação no SUS. Brasília, DF, jul. 2006. 40p. (Série Pactos pela Saúde, v. 3). Disponível em: <http://bvsms.saude. gov.br/bvs/publicacoes/regionalizacao2006.pdf>.

${ }^{35}$ MIRANDA, J. G. Direito da seguridade social. Rio de Janeiro: Elsevier, 2007.
} 
Sob esse prisma de análise, um estudo sustent $\mathrm{a}^{36} \mathrm{o}$ discurso dos profissionais ao atestarem que a judicialização da saúde, no modelo de prestação pública de serviços, está contribuindo para a criação de um SUS de duas portas: uma para os que acessam o Judiciário e têm acesso a irrestritos recursos estatais para o atendimento de seus problemas de saúde, e outra para os demais cidadãos, que acabam tendo acesso mais limitado ainda, em função da necessidade de redirecionamento da alocação dos recursos devido ao beneficiamento dos que acessaram o sistema pela porta alternativa.

Essa espécie de sistema paralelo de saúde decorrente do crescimento desenfreado de medidas judiciais, principalmente as individuais, pode trazer sérias consequências para o equilíbrio do planejamento orçamentário da saúde ${ }^{37}$, sendo recomendada a busca do equilíbrio entre concessão do direito individual e políticas públicas para que o impacto orçamentário dessas ações não torne inviável a execução da política de saúde para o coletivo. Essa questão foi alvo do discurso dos profissionais.

Entrevista 1 - Médico: "Eu acho que isso trava o sistema e acaba diminuindo o acesso ao sistema de saúde. Como o orçamento é único, ela [a judicialização] retira acesso de outras pessoas porque o orçamento diminui."

Entrevista 27 - Médico: “Gastam-se milhões e milhões nesses mandados. Não tem licitação para comprar, daí deitam e rolam, cobram o absurdo que for porque tem que ser cumprido rápido."

A aplicação de recursos exorbitantes para o atendimento de necessidades individuais pode prejudicar ou até mesmo impedir a implementação da política de saúde e de outras políticas públicas para a população ${ }^{38}$, afirmação que é sustentada pelos trechos transcritos acima.

Para se promover a real proteção do direito à saúde, é necessária a adoção de determinados cuidados para que não se crie uma ilusão de resolução de problemas ou para não mascarar a dificuldade maior da saúde pública com a resolução pontual de problemas $^{39}$. Sobre isso, os sujeitos comentaram que:

Entrevista 16 - Médico: "Faz perder a consciência do problema de saúde que existe hoje em dia e faz mascarar os responsáveis principais por isso."

Entrevista 32 - Assistente Social: "E a tendência é essa individualização e não coletivização, ou seja, você não gera política pública.”

\footnotetext{
${ }^{36}$ FERRAZ, O. L. M.; Wang, D. W. L. As duas portas do SUS. Folha de S. Paulo. São Paulo, 22 jun. 2014. Opinião.

${ }^{37}$ SILVA, L. C. Judicialização da saúde: em busca de uma contenção saudável. Revista Âmbito Jurídico, Rio Grande, v. 16, n. 112, maio 2013. Disponível em: <http://www.ambito-juridico.com.br/site/index.php/?n_ link=revista_artigos_leitura\&artigo_id=13182\&revista_caderno=9>. Acesso em: 16 ago. 2013

${ }^{38}$ NEVES, M. Judiciário intensifica privilégios no acesso à saúde. Consultor Jurídico, 19 de outubro de 2013. Disponível em: <http://www.conjur.com.br/2013-out-19/observatorio-constitucional-judiciario-intensificaprivilegios-acesso-saude>. Acesso em: 20 out. 2013.

${ }^{39}$ DALLARI, D. A. O poder dos juízes. 2. ed. São Paulo: Saraiva, 2002.
} 
Estes fragmentos ressaltam a tese de que os moldes pelos quais a judicialização da saúde vem sendo praticada não resolvem, nem mesmo colaboram para resolver, o complexo problema da saúde pública. Informa-se que, no ano de 2013, foram gastos cerca de $\mathrm{R} \$ 1$ bilhão com medidas judiciais, sendo que essa verba foi subtraída do orçamento destinado ao atendimento da saúde de toda a população. Portanto, o que já é insuficiente torna-se mais escasso, podendo comprometer ainda mais o desenvolvimento das políticas de saúde ${ }^{40}$.

O debate acerca da judicialização da saúde deve ter como ponto de partida a noção de que o cenário de escassez de recursos é real e de que as necessidades tendem a serem maiores do que pode atender o orçamento público. Essa constatação parece óbvia tanto para os economistas quanto para os gestores públicos, mas parece não fazer sentido ou não importar para os operadores do direito ${ }^{41}$.

Os profissionais de saúde associaram a ineficiência de gestão do Estado à promoção dos processos judiciais:

Entrevista 18 - Médico: "Então, é mais ou menos isso: o gestor tem essa dificuldade de, por si só, tentar fazer com que tudo esteja engrenado. E vamos dizer que o gestor tenha esse comprometimento, mas quem está acima dele, o que faz o planejamento das políticas de saúde, não tenha esse comprometimento porque está interessado na política, na distribuição do poder político."

Entrevista 1 - Médico: "Só que aí entra a questão do Estado Deus: o Estado não é capaz de atender isso tudo, seja por problema de gestão, seja por deficiência de verba."

$\mathrm{O}$ “acesso universal e igualitário às ações e serviços de saúde, assegurado no artigo 196 da Constituição, transformado em gratuito pela legislação infraconstitucional, é utópico e gera expectativas inalcançáveis para os cidadãos" ${ }^{32}$. Assim, os serviços de saúde no Brasil oferecem um fértil terreno para a judicialização devido a uma ampla Carta Constitucional e a uma frágil engrenagem dos serviços de saúde, conferindo ao Poder Judiciário o papel de decidir sobre os rumos do SUS ${ }^{43}$.

Nesse sentido, o Poder Judiciário vem assumindo a titularidade para a manutenção dos preceitos constitucionais e vem sendo provocado a solucionar conflitos entre o cidadão e o poder público (representado pelo Legislativo e Executivo), que

\footnotetext{
${ }^{40}$ VENTURA, M. et al. op. cit.

${ }^{41}$ WANG, D. W. L. Escassez de recursos, custos dos direitos e reserva do possível na jurisprudência do Supremo Tribunal Federal. Rev. Direito GV, São Paulo, v. 4, n.2, p. 539-568, 2008. Disponível em: <http:// www.scielo.br/pdf/rdgv/v4n2/a09v4n2.pdf>.

${ }^{42}$ TORRES, R. L. Teoria dos direitos fundamentais. 2. ed. Rio de Janeiro: Renovar, 2004.

${ }^{43}$ SANT'ANA, J. M. B. Essencialidade e assistência farmacêutica: um estudo exploratório das demandas judiciais individuais para acesso a medicamentos no Estado do Rio de Janeiro. Rio de Janeiro. 93f. 2009. Dissertação (Mestrado em Saúde Pública) - Escola Nacional de Saúde Pública Sergio Arouca, Rio de Janeiro, 2009.
} 
não desempenha seu papel de garantir os direitos, (como o direito à saúde) seja por ideologia, seja por má gestão, seja por escassez de recursos ${ }^{44}$. Isso aponta para uma crise no Estado Social face às dificuldades encontradas na implementação das políticas de saúde, à busca pela garantia judicial dos direitos sanitários e ao poder supremo da magistratura na decisão dos rumos do SUS.

\section{Considerações finais}

Considerando que a representação social pode ser definida como uma visão funcional do mundo, que permite que o indivíduo e o grupo deem sentido a suas condutas e compreendam a realidade a partir de seus próprios cenários de referência, conclui-se que a construção da representação social emergiu da prática dos profissionais de saúde, sendo o cenário de atuação o alicerce para a elaboração dos conceitos e imagens desse grupo acerca da judicialização.

No processo de análise das entrevistas, foi possível perceber que os participantes estabelecem um nexo cronológico na judicialização, apresentando como fato histórico-temporal a consolidação da concepção de saúde como direito; essa concepção é o fator que leva a uma reação em cadeia que permitiu a elaboração e a organização de um pensamento social acerca do objeto investigado.

Para os participantes desta pesquisa, são as limitações do SUS real que dão início ao movimento da engrenagem da judicialização. Portanto, neste estudo, evidenciou-se que a judicialização da saúde apresenta forte interface com a vida cotidiana desses sujeitos e foi justamente por meio dessa dimensão prática que se iniciou o processo de elaboração de um constructo representacional sobre o objeto.

Para esses sujeitos, é fato irrefutável que a judicialização facilita e, por vezes, é o fator determinante do acesso da população às ações e aos serviços públicos de saúde, mesmo que essa estratégia promova, predominantemente, a resolução de problemas pontuais, não sendo capaz de gerar política ou de aprimorar a política em voga, assim como tende a individualizar as ações em detrimento do coletivo.

A atuação do Judiciário, apesar de ser positiva no resultado final, garantindo de fato o acesso a determinado recurso para os que a ele recorrem, tem uma avaliação global negativa por parte dos participantes da pesquisa. A concretude dessa atuação suscita a identificação de inconformidades protocolares e inadequações nas decisões exaradas. Tais decisões, nem sempre acertadas, repercutem na prática dos profissionais de saúde porque testemunham o aprofundamento das desigualdades - com o agravamento de pessoas que deixam de ter acesso a determinado recurso

\footnotetext{
${ }^{44}$ KEINERT, T. M. M. Direitos Fundamentais, direito à saúde e papel do executivo, legislativo e judiciário: fundamentos de direito constitucional e administrativo. In: KEINERT, T. M. M.; PAULA, S. H. B.; BONFIM, J. R. A. (Org.). As ações Judiciais no SUS e a promoção do direito à saúde. São Paulo: Instituto de Saúde, 2009. p. 87-108.
} 
terapêutico em função da obrigatoriedade de cumprimento de um mandado judicial. Essa percepção dá contorno a um sentimento de injustiça.

Os apontamentos dos sujeitos propiciaram a reflexão sobre um grande paradoxo estabelecido pelas decisões judiciais para acesso ao sistema de saúde: a tendência a promover privilégio a um indivíduo versus a política de saúde e a prerrogativa constitucional que compreende a saúde como direito em uma perspectiva universal.

Da produção discursiva dos sujeitos, também deriva a necessidade urgente de estabelecimento de diálogo entre os atores sociais e as instâncias jurídicas e administrativas envolvidas no contexto da judicialização da saúde. Tal diálogo é fundamental para a compreensão dos diversos prismas de observação e interpretação da realidade imposta pelo objeto de estudo e para a construção conjunta de propostas que de fato possam modificar a realidade atual das práticas.

De posse das reflexões apresentadas, é indiscutível que as decisões judiciais, frente aos entraves evidenciados para o desenvolvimento pleno do SUS de acordo com suas doutrinas e filosofias, contribuíram para o fortalecimento do debate acerca da necessidade de reavaliação das estratégias para a garantia da efetivação do direito à saúde.

Acredita-se que esta produção possa ser um instrumento para melhor compreensão das complexas teias políticas, sociais e ideológicas envolvidas na judicialização da saúde, bem como do impacto da judicialização na consolidação do modelo de saúde desenhado para nosso país. Os resultados apontam para uma representação social em fase de consolidação e predominantemente negativa.

Destaca-se que, para que haja o enriquecimento desse debate, torna-se imperiosa sua ampliação envolvendo os profissionais de saúde e pesquisadores da temática a fim de que, baseados em evidência, possam pensar propostas para a resolução dos pleitos, principalmente os mais recorrentes. Espera-se, dessa forma, que ocorra a promoção de melhorias no resultado final da assistência direta aos usuários que buscam as instituições públicas de saúde para serem atendidos em suas necessidades de saúde. Caracteriza-se, assim, um desafio maior, que caminha no sentido de fazer avançar a democracia e a cidadania.

\section{Referências}

BRASIL. Ministério da Saúde. Regionalização Solidária e Cooperativa. Orientações para sua implementação no SUS. Brasília, DF, jul. 2006. 40p. (Série Pactos pela Saúde, v. 3). Disponível em: <http://bvsms.saude.gov.br/bvs/publicacoes/regionalizacao2006.pdf >.

Ministério da Saúde. Secretaria-Executiva. Subsecretaria de Planejamento e Orçamento. Sistema de planejamento do SUS: uma construção coletiva: instrumentos básicos. 2. ed. Brasília-DF, 2009. Disponível em: <http://bvsms.saude.gov.br/bvs/publicacoes/ caderno2_planejasus_2ed.pdf $>$. 
BRASIL. Ministério da Saúde. Secretaria Executiva. Sistema Único de Saúde (SUS) descentralização. Brasília-DF, 2000. 32p.

CAMPILONGO, C. F. O direito na sociedade complexa. São Paulo: Max Limonad, 2000.

DALLARI, D. A. O poder dos juízes. 2. ed. São Paulo: Saraiva, 2002.

FERRAZ, O. L. M.; Wang, D. W. L. As duas portas do SUS. Folha de S. Paulo. São Paulo, 22 jun. 2014. Opinião.

FERREIRA, S. L.; COSTA, A. M. Núcleos de assessoria técnica e judicialização da saúde: constitucionais ou inconstitucionais? Rev. Seção Judic. Rio de Janeiro, Rio de Janeiro, v. 20, n. 36, p. 219-240, abr. 2013. Disponível em: <https://bdjur.stj.jus.br/jspui/bitstream/2011/74787/ nucleos_assessoria_tecnica_ferreira.pdf $>$.

GARLET, E. R. et al. Organização do trabalho de uma equipe de saúde no atendimento ao usuário em situações de urgência e emergência. Texto contexto enferm., Florianópolis, v. 18, n. 2, p.2 66-272, abr./jun. 2009. Disponível em: <http://www.scielo.br/pdf/tce/v18n2/09>.

GOMES, F. F. C. A judicialização da saúde em Minas Gerais: uma avaliação dos processos judiciais relacionados aos procedimentos ambulatoriais e hospitalares no período 1999-2009. 2013. 98f. Dissertação (Mestrado em Saúde Pública) - Faculdade de Medicina, Universidade Federal de Minas Gerais, Belo Horizonte, 2013.

JODELET, D. Folies et représentations sociales. Paris: PUF, 1989.

KEINERT, T. M. M. Direitos Fundamentais, direito à saúde e papel do executivo, legislativo e judiciário: fundamentos de direito constitucional e administrativo. In: KEINERT, T. M. M.; PAULA, S. H. B.; BONFIM, J. R. A. (Org.). As ações Judiciais no SUS e a promoção do direito à saúde. São Paulo: Instituto de Saúde, 2009. p. 87-108.

LEÃO, T. M. Direito sanitário: saúde e direito, um diálogo possível. Revista de Direito Sanitário, São Paulo, v. 12, n. 1, p. 277-292, jun. 2011. Disponível em: <http://www.revistas.usp.br/ rdisan/article/view/13244/15060>. Acesso em: 26 ago. 2012.

MACHADO, F. R. S.; Dain, S. A audiência pública da saúde: questões para a judicialização e para a gestão de saúde no Brasil. Rev. Adm. Pública, Rio de Janeiro, v. 46, n. 4, p. 1017-1036, jul./ago. 2012. Disponível em <http://www.scielo.br/scielo.php?script=sci_arttext\&pid=S003476122012000400006\&lng=pt\&nrm=iso $>$. Acesso em: 23 maio 2014. http://dx.doi.org/10.1590/ S0034-76122012000400006.

MARQUES, S. B. Judicialização do direito à saúde. Revista de Direito Sanitário, São Paulo, São Paulo, v. 9, n. 2, p. 65-72, jul./out. 2008. Disponível em: <https://www.revistas.usp.br/ rdisan/article/view/13117/14920>.

MEDICI, A. C. Judicialização, integralidade e financiamento da saúde. Diagn. Tratamento. São Paulo, v. 15, n. 2, p. 81-86, 2010. Disponível em: <http://files.bvs.br/upload/S/1413-9979/2010/ v15n2/a81-87.pdf>. Acesso em: 05 out. 2011. 
MIRANDA, J. G. Direito da seguridade social. Rio de Janeiro: Elsevier, 2007.

MOCELIN, C. E. Demandas judiciais na saúde pública: instrumentos para a efetivação do direito à saúde e/ou novos arranjos na gestão e organização do SUS. Rev. gestão desenvolv. Contexto - GEDECON, Cruz Alta, v. 1, n. 1, p. 100-117, 2013. Disponível em: <http:// revistaeletronica.unicruz.edu.br/index.php/GEDECON/article/view/311/226>.

MOSCOVICI, S. La psychanalyse son image et son public. Paris: Presses Universitaires de France, 1976.

NEVES, M. Judiciário intensifica privilégios no acesso à saúde. Consultor Jurídico, 19 de outubro de 2013. Disponível em: <http://www.conjur.com.br/2013-out-19/observatorioconstitucional-judiciario-intensifica-privilegios-acesso-saude>. Acesso em: 20 out. 2013.

OLIVEIRA, D. C. Análise de conteúdo temático-categorial: uma proposta de sistematização. Rev. Enferm. UERJ, Rio de Janeiro, v.16, n.4, p. 569-576, out./dez. 2008. Disponível em: <http:// www.facenf.uerj.br/v16n4/v16n4a19.pdf>.

PINHEIRO, R; Mattos, R. A. (Org.). Os sentidos da integralidade na atenção e no cuidado à saúde. Rio de Janeiro: CEPESC/UERJ- IMS/ABRASCO, 2001.

ROUQUETE, M. L. Representações e práticas sociais: alguns elementos teóricos. In: MOREIRA, A. S. P.; OLIVEIRA, D. C. (Orgs.). Estudos interdisciplinares em representação social. 2. ed. Goiânia: AB Ed., 2000. p. 27-38.

SÁ, C. P. A construção do objeto de pesquisa em representações sociais. Rio de Janeiro: EdUERJ, 1998.

SANT'ANA, J. M. B. Essencialidade e assistência farmacêutica: um estudo exploratório das demandas judiciais individuais para acesso a medicamentos no Estado do Rio de Janeiro. Rio de Janeiro. 93f. 2009. Dissertação (Mestrado em Saúde Pública) - Escola Nacional de Saúde Pública Sergio Arouca, Rio de Janeiro, 2009.

SANTOS, L. A gestão do SUS: limites de sua autonomia diante da judicialização da saúde, das ações administrativas e judiciais do Ministério Público e da atuação dos órgãos de controle. In: BRASIL. Ministério do Planejamento Gestão e Orçamento. Seminário Direito, Gestão e Democracia Limites da Autonomia e do Controle do Poder Executivo. Brasília-DF: Imprensa Nacional, 2010. p. 88-95.

SARLET, F.; Figueiredo, M. F. Algumas considerações sobre o direito fundamental à proteção e promoção da saúde aos 20 anos da Constituição Federal de 1988. Versão originalmente publicada na Revista de Direito do Consumidor, [S. I.], v. 17, n. 67, p. 125-172, 2008. Disponível em: $<$ http://www.stf.jus.br/arquivo/cms/processoAudienciaPublicaSaude/anexo/O_direito_a_ saude_nos_20_anos_da_CF_coletanea_TAnia_10_04_09.pdf >. Acesso em:16 set. 2011.

SILVA, L. C. Judicialização da saúde: em busca de uma contenção saudável. Revista Âmbito Jurídico, Rio Grande, v. 16, n. 112, maio 2013. Disponível em: <http://www.ambito-juridico. com.br/site/index.php/?n_link=revista_artigos_leitura\&artigo_id=13182\&revista_ caderno=9>. Acesso em: 16 ago. 2013. 
SPEDO, S. M.; Pinto, N. R. S.; Tanaka, O. Y. O difícil acesso a serviços de média complexidade do SUS: o caso da cidade de São Paulo, Brasil. Physis, Rio de Janeiro, v. 20, n. 3, 2010. Disponível em: <http://www.scielo.br/scielo.php?script=sci_arttext\&pid=S010373312010000300014\&lng=en\&nrm=iso $>$. Acesso em: 03 mar. 2014. http://dx.doi.org/10.1590/ S0103-73312010000300014.

TORRES, R. L. Teoria dos direitos fundamentais. 2. ed. Rio de Janeiro: Renovar, 2004.

VENTURA, M. et al. Judicialização da saúde, acesso à justiça e a efetividade do direito à saúde. Physis, Rio de Janeiro, v. 20, n. 1, p. 77-100, 2010. Disponível em: <http://www.scielo.br/ scielo.php?script=sci_arttext\&pid=S0103-73312010000100006 >. http://dx.doi.org/10.1590/ S0103-73312010000100006.

WANG, D. W. L. Escassez de recursos, custos dos direitos e reserva do possível na jurisprudência do Supremo Tribunal Federal. Rev. Direito GV, São Paulo, v. 4, n.2, p. 539-568, 2008. Disponível em: <http://www.scielo.br/pdf/rdgv/v4n2/a09v4n2.pdf>.

Raquel de Souza Ramos - Doutora em Enfermagem pela Universidade do Estado do Rio de Janeiro (UERJ); mestre em Enfermagem pela UERJ; graduada em Enfermagem pela UERJ. Enfermeira da Coordenadoria de Enfermagem do Hospital Universitário Pedro Ernesto e do Serviço de Cirurgia Abdômino-Pélvica do Instituto Nacional de Câncer José Alencar Gomes da Silva. Rio de Janeiro/RJ, Brasil.E-mail: kakelramos@gmail.com.

Antonio Marcos Tosoli Gomes - Pós-Doutor em Enfermagem pela Universidade Federal de Santa Catarina; doutor em Enfermagem pela Universidade Federal do Rio de Janeiro; mestre em Enfermagem pela Universidade do Estado do Rio de Janeiro (UERJ). Professor Titular da Faculdade de Enfermagem da UERJ. Rio de Janeiro/RJ, Brasil.

Raphael Mendonça Guimarães - Doutor em Saúde Coletiva pela Universidade Federal do Rio de Janeiro. Pesquisador da Fundação Oswaldo Cruz. Rio de Janeiro/RJ, Brasil.

Érick Igor dos Santos (in memorian) - Doutor em Enfermagem pela Universidade do Estado do Rio de Janeiro. Professor Assistente da Faculdade de Enfermagem da Universidade Federal Fluminense. Rio das Ostras/RJ, Brasil. 